\title{
Effectiveness of nursing interventions in preventing and treating radiotherapy side effects in cancer patients: a systematic review*
}

\author{
Efetividade das intervenções de enfermagem na prevenção e tratamento dos efeitos \\ colaterais da radioterapia no paciente com câncer: uma revisão sistemática \\ Efectividad de las intervenciones de enfermería en la prevención y en el tratamiento de los \\ efectos colaterales de la radioterapia en pacientes con cáncer: una revisión sistemática
}

How to cite this article:

Abreu AM, Fraga DRS, Giergowicz BB, Figueiró RB, Waterkemper R. Effectiveness of nursing interventions in preventing and treating radiotherapy side effects in cancer patients: a systematic review. Rev Esc Enferm USP. 2021;55:e03697. doi: https://doi.org/10.1590/S1980-220X2019026303697

\section{Aline Moraes de Abreu ${ }^{1}$ \\ Duan Renato da Silva Fraga ${ }^{1}$ \\ Bruna Bastos Giergowicz ${ }^{1}$ \\ Rosália Borges Figueiró ${ }^{2}$ \\ Roberta Waterkemper ${ }^{1}$}

\footnotetext{
* Extracted from thesis: "Cuidado centrado no paciente em radioterapia: construção de Plano de cuidado de Enfermagem a partir de diagnósticos e intervenções de Enfermagem, Universidade Federal de Ciências da Saúde de Porto Alegre, 2019.

${ }^{1}$ Universidade Federal de Ciências da Saúde de Porto Alegre, Porto Alegre, Porto Alegre, RS, Brazil.

2 Universidade do Vale do Rio dos Sinos, São Leopoldo, RS, Brazil.
}

\begin{abstract}
Objective: To synthesize the best available evidence on the effectiveness of nursing interventions in radiotherapy patient care and to summarize the evidence on the experience and acceptability of interventions reported by health professionals involved in the prevention and treatment of side effects. Method: A mixed-method systematic review. Quantitative and qualitative studies are presented. Results: Twelve studies published between 2013 and 2017 were included. Most interventions found focused on skin care, oral care, nausea and vomiting and nursing consultation. In accordance with high level of evidence and recommendation grade of the studies, the use of Calendula officinalis and thyme honey were considered effective for preventing and treating radiodermatitis and mucositis, respectively. Conclusion: The quality of evidence of nursing interventions is weak. Although there are studies with a strong design and a high level of evidence, publication of nursing interventions is not enough and does not present a high quality to support practice to plan an effective patient-centered care.
\end{abstract}

\section{DESCRIPTORS}

Neoplasms; Radiotherapy, Oncology Nursing; Patient-Centered Care; Review.
Corresponding author:

Aline Moraes de Abreu

Rua General Câmara, 453, Apto. 405

CEP 90010-230 - Porto Alegre, RS, Brazil

alineurug@yahoo.com.br
Received: 09/09/2019

Approved: 10/03/2020 


\section{INTRODUCTION}

Cancer is a disease that can affect multiple organs of the human body, being characterized by DNA modifications and exacerbated cell multiplication, it can form malignant tumors capable of multiplying to other regions and lead the individual to death. Around the world, approximately 8.8 million people die from cancer every year, most of them in developing countries. It is classified as a noncommunicable disease, such as diabetes, cardiovascular and chronic lung disease, and it is responsible for $71 \%$ of all deaths worldwide ${ }^{(1)}$.

In Brazil, 625,000 new cases of cancer are estimated to the period between the years 2020-2022, annually. The most common types of cancer in men, with the exception of non-skin cancer melanoma, will be prostate (29.2\%), colon and rectum (9.1\%), lung (7.9\%), stomach (5.9\%) and oral cavity (5.0\%). In women, except for non-melanoma skin cancer, breast (29.7\%), colon and rectum (9.2\%), cervix (7.4\%), lung (5.6\%) and thyroid cancer (5.4\%) will be among the main types. Life expectancy increase of the population also stimulates the development of chronic degenerative diseases, such as cancer ${ }^{(1-3)}$.

In accordance with a national study, the distribution of incidence in the Brazilian regions shows that the Southeast region concentrates more than $60 \%$ of the incidence, followed by the Northeast $(27.8 \%)$ and South (23.4\%) regions. There is, however, a great variation in the magnitude and types of cancer between the different regions of Brazil. In the South and Southeast regions, the pattern of incidence shows that prostate and female breast cancers, as well as lung and bowel cancers are more incident. In Rio Grande do Sul, 30,260 new cases of all cancers and 46,060 cases of malign disease were estimated in 2020. In the capital city of Porto Alegre, female breast cancer is the most incident, with 660 new cases ${ }^{(1,4)}$.

Among the modalities of curative and or palliative treatment chemotherapy and radiotherapy are the most common. Chemotherapy is being increasingly used given its specificity and, in recent years, has been advanced due to the treating of specific neoplasms. Moreover, the refinement of body receptor types has strengthened the preference for antineoplastic therapy ${ }^{(5)}$. However, cytotoxic effects still need to be eliminated from such drugs, which are currently only controlled with antiemetics, for example.

On the other hand, radiotherapy, through the emission of ionizing radiation in the region of the tumor, treats it locally with few systemic effects, becoming an advantage over chemotherapy, with its systemic adverse effects, which can generate numerous unpleasant symptoms like emesis. Ionizing radiation aims to eliminate or reduce the growth rate of tumor cells, which end up failing to expand to other areas and may lead to cell death. The radiation emitted on the tumor is absorbed by the body through the normal process of other drugs, such as the passage through biotransformation, where these ions are metabolized and excreted by the liver and kidneys. In this process, the electrons irradiated on the tumor interact with the cancer cells, aiming to eliminate them, inducing apoptosis, or restraining their division ${ }^{(6)}$. As any treatment involving chemical principles, radiotherapy in any of its modalities also has adverse effects. These effects appear on average in the third week of radiation treatment. Among these, the most prevalent and clinically significant effects are tiredness, loss of appetite, difficulty in food intake and skin reactions, called radiodermatitis ${ }^{(7)}$.

Nurses who work in radiotherapy have a relevant role in health care for this population, mainly in the prevention and treatment of the specific adverse reactions of this modality of oncologic therapy. Hence, the Nursing Process, a method of private nurse assistance, must be effectively used in clinical practice. Without this, the care provided by nurses and their team is not based on nursing science, becoming only a routine of repetition of care interventions and actions and, often, of medical prescription execution. The role of nurses in radiotherapy has an impact both on the preparation of patients for examination and on the control of adverse effects, through preventive and care actions ${ }^{(8)}$.

According with Federal Nursing Council from Brazil $(\mathrm{COFEN})^{(9)}$, the competencies of nursing professionals who work in radiotherapy are: to act in the prevention, treatment and rehabilitation of clients submitted to ionizing radiation, participation in quality assurance programs in services that use ionizing radiation and continue education, and to comply with norms, regulations and legislation relevant to the areas of operation. In the same way, promoting interaction among the multiprofessional team, seeking to guarantee comprehensive care to patients and their families, and recording information and statistical data pertinent to the nursing assistance and the technical and scientific updates allow nurses to act effectively in the area of radiation ionizing agents.

Thus, nursing care is fundamental for the improvement of life quality of patients who are already so fragile, which explains the social and professional relevance of this research. In view of the above, the following guiding question emerges: What is the effectiveness of nursing interventions to cancer patients submitted to radiotherapy and who can base the construction of nursing care plans? The purpose of this review was to synthesize the best available evidence on the effectiveness of nursing interventions in patients undergoing radiotherapy and to synthesize the best available evidence on the experience and acceptability of the interventions as reported by the contacts and health professionals involved in the prevention and treatment of side effects.

\section{METHOD}

\section{Study TYPE}

This is a systematic review that considers multiple methods in nursing. The study was developed from a protocol elaborated following the guidelines of PRISMA and the Joanna Briggs Institute (JBI) method and submitted in the Prospective Registry System of Systematic Reviews (PROSPERO). This review was reported according to PRISMA/JBI ${ }^{(10-11)}$.

\section{SCENARIO}

Studies with patients undergoing outpatient radiotherapy treatment were considered in this review. The quantitative component of the review considered experimental and observational 
studies, including randomized and non-randomized controlled trials (RCTs), uncontrolled trials or quasi-experimental studies, clinical community trials, before-and-after studies, prospective and retrospective cohort studies, case-control studies and analytical cross-sectional studies. The evidence level of quantitative studies was assessed using the JBI levels of evidence for effectiveness. The qualitative component of the review considered studies, including but not limited to, phenomenology, ethnography and action-research studies. Descriptive qualitative studies that described the experience and acceptability or those describing the effects of the experience were also considered. The evidence level of qualitative studies was assessed using study designs classification ${ }^{(10)}$.

In the quantitative component, this review considered studies that included nursing interventions to prevent and/ or treat radiotherapy side effects in cancer patients with any design. In the qualitative component, in addition to interventions, studies of nurses with the report of meanings of their practice and patient/families reports of meanings of care were included.

The quantitative component of the review considered the following outcomes: clinical development of any adverse effect in patients undergoing radiotherapy treatment, preventive and treatment effects in the use of any intervention planned and/or performed by nursing.

\section{Selection CRiteria}

Inclusion criteria were articles that portrayed the study theme (nursing interventions in radiotherapy); articles published between 2013 and 2017); available in full version in the text databases searched in English, Portuguese and Spanish. Exclusion criteria were monographs; simple or expanded abstracts; studies that addressed other specialties or lesions not related to radiotherapy.

Studies that included patients with cancer of different diagnoses submitted to radiotherapy, the effectiveness of the care actions prescribed by the nurses to prevent the treatment of reactions to radiotherapy, as well as studies that addressed the cost-benefit of such actions were considered. Qualitative research included studies describing the perceptions/feelings of patients with cancer of different diagnoses submitted to radiotherapeutic treatment and their families on professional care actions, as well as reports of experience. Descriptive studies of different qualitative approaches developed by nurses who revealed perceptions/feelings related to care to cancer patients from different diagnoses submitted to radiotherapy were also considered. Articles that portrayed the study theme (nursing interventions in radiotherapy); articles published between 2013 and 2017; available in full version in the text databases searched in English, Portuguese and Spanish. Studies that described issues related to the cost of treatment, including the professional's work time, physical space, material for its completion and products for treatment were also included.

\section{Data collection}

Data collection from scientific publications took place from May 2018 to May 2019, conducted simultaneously by two researchers (one holds a professional master's degree and the other is a scientific initiation scholar). The searches were carried out in the following electronic bibliographic databases: LILACS (Latin American and Caribbean Literature in Health Sciences), CINAHL, SciELO, ScienceDirect, Web of Science, Complete MEDLINE and BDENF, using descriptors in health sciences (DeCS) and keywords in Portuguese, English and Spanish through the association with Boolean operators "and", "or", and "not".

The review was conducted with three reviewers. In the first time by the professional master (R1) and scientific initiation scholar (R2). If there was disagreement between them, in -a second time, a third reviewer was called to make the decision of inclusion or not. It was performed simultaneously by R1 and R2 in shared worksheets using Microsoft Excel and checked weekly with face-to-face meeting. Initial tests were made to suit the collection process. This initiation was carried out without the help of specialized software with the included/excluded articles inserted into spreadsheets. As inclusion decisions were or were not made, colors were assigned to identify: Included, Excluded and Doubt. The reviewers assessed the quantitative papers selected for retrieval prior to inclusion using the model of standardized critical appraisal instruments for quantitative and qualitative studies and constructed by the authors. Any disagreements that arose between the reviewers were solved through discussion, or with a third reviewer. To report results, the initials of Evidence Level (EL), Evidence Strength (ES) and Recommendation Grade (RG) with their respective classifications to show the quality of the interventions were used.

The quantitative data were extracted from papers using a standardized data extraction tool developed by the authors, including specific details about the interventions, populations, study methods, and outcomes of significance to the question and specific objectives of the review. Qualitative data were extracted from papers included in this review by using the standardized data extraction tool elaborated by the authors including specific details about the population, study method and main findings of the phenomenon of interest. The critical appraisal of selected quantitative studies was based on instruments proposed by the Joanna Briggs Institute (JBI) ${ }^{(10,12)}$ to assess the level of evidence, degree of recommendation, strength of recommendation and risk of bias. Although the JBI establishes Efficacy, Diagnosis, Prognosis, Costs and Significance as a level of evidence evaluation, in this study we used only the Efficacy and Significance ratings. The levels of evidence for Efficacy are designed to align with the preclassification approach based on the study design, which is updated or reduced depending on several factors.

After the evaluation of the level of evidence, the classification of the strength and degree of recommendation were carried out. According to the $\mathrm{JBI}^{(10,12)}$, the strength of recommendation is considered in a binary system $\mathrm{A}$ or $\mathrm{B}$ and the degree of recommendation can be classified into strong and weak. Due to clinical and methodological heterogeneity between included quantitative studies, statistic pooling by meta-analysis was not possible and the results are therefore 
presented in narrative form. Heterogeneity was identified in the research designs (methodological heterogeneity) and measured outcomes (clinical heterogeneity). The included studies evaluated for this type of analysis were $13,14,15$, $16,17,18,19,20,21$, and 22. Qualitative research findings are presented in narrative form as well, as only two studies (23 and 24) were included in this review.

\section{ETHICAL ASPECTS}

The present study was extracted from the master's thesis Cuidado centrado no paciente em radioterapia: construção de plano de cuidado de enfermagem a partir de diagnósticos e intervençôes de enfermagem, which was approved by the Ethics Committee of Irmandade da Santa Casa de Misericórdia de Porto Alegre on August 16th, 2018, under number 2.825.05.

\section{RESULTS}

\section{StUdy DESIGN DESCRIPTIONS}

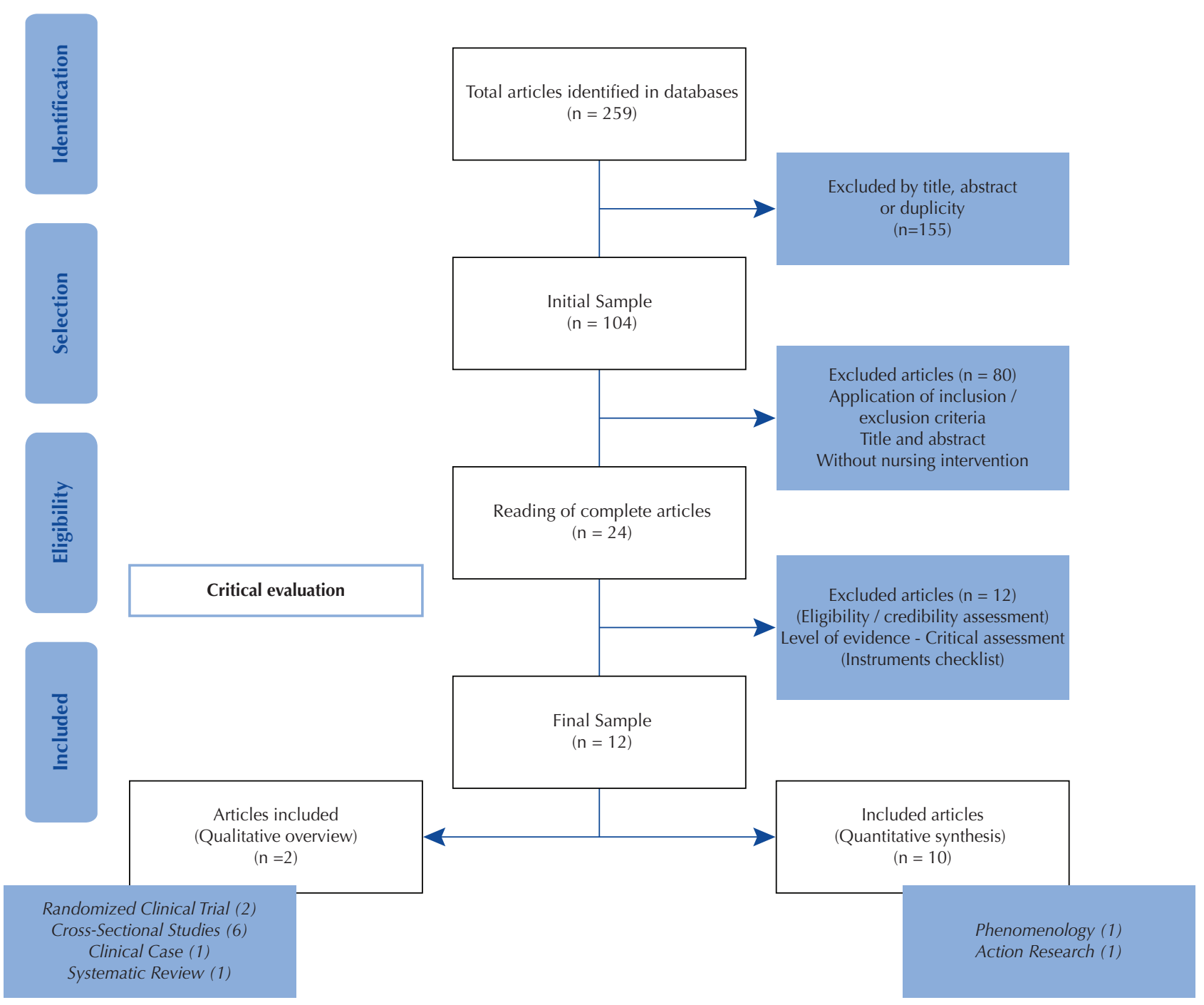

Figure 1 - Development flow diagram of the systematic review for inclusion and exclusion of studies.

The search identified 259 potentially relevant studies from the first and the second searches made in May 2018 and May 2019 (Figure 1). Of these, 155 records were excluded because they were duplicated and 104 studies were screened for relevance to the review's inclusion criteria. A total of 12 studies likely to be relevant were retrieved and assessed for eligibility. Ten of the studies were critically appraised for methodological quality and included in this systematic review. Of these 12 studies, two were qualitative.

The articles included in this review present nursing interventions focused on physical signs and symptoms and the care process related to radiotherapy. Only two studies were designed about effectiveness ${ }^{(13-14)}$ - one observational ${ }^{(15)}$ and the other methodological ${ }^{(16)}$, four were cross-sectional ${ }^{(17-20)}$, 
one was a systematic review ${ }^{(21)}$, one was a clinical report ${ }^{(22)}$, one was phenomenological ${ }^{(23)}$, and one was an action research ${ }^{(24)}$.

The physical focus was skin care, oral care and nausea/ vomiting. Oral mucositis and radiodermatitis were reported on effectiveness and cross-sectional studies. The first study was a randomized controlled trial $(\mathrm{RCT})^{(14)}$ with 72 head and neck cancer patients who were divided either into an intervention group (43) or a control group (43). The study was designed to provide evidence on the effectiveness of thyme honey on oral mucositis management. The results were measured as cumulative incidence in the three intervention groups and analyzed through a baseline comparison between the two groups that were assessed using a test for the age and level of radiation dose, and the t-test for gender and education. The severity of symptoms, weight and life quality are presented as mean \pm standard deviations and the prevalence of severe oral mucositis as frequencies $(\mathrm{N})$ and percentages (\%). A generalized estimating equation was utilized for the prediction of the intervention effect.

Odynophagia is another reaction identified. As long as the treatment is made, patients can present swallow problems and pain. The second was a retrospective study ${ }^{(15)}$ aimed to make observations from 131 patient-centered nursing practices used to generate predictive models for odynophagia needing prescription for pain medication during external beam lung radiotherapy for non-small cell and small cell lung cancer. Three multivariate logistic models were evaluated in repeat cross-validation: a manual-stepwise model and two supervised machine learning models.

The third study was a randomized double-blind controlled clinical trial ${ }^{(13)}$ that aimed to evaluate the efficacy of Calendula officinalis in relation to essential fatty acids for the prevention and treatment of radiodermatitis. The study was made with 51 patients with head and neck cancer in radiotherapy divided into two groups: control (27) and experimental (24). The primary endpoint was the development of radiodermatitis, evaluated according to the degree of toxicity, in the criteria of the Radiation Therapy Oncology Group. The skin of the participant in the field of irradiation was evaluated in the first session of radiotherapy, every five sessions and after 30 days of termination of treatment and skin toxicity, a trained member of the research team performed the assessment. Chisquare, Fisher's exact, and Williams' G tests were used in the categorical variables. For the quantitative variables, Mann-Whitney and Wilcoxon U tests were used. Survival curves were estimated using the Kaplan-Meier method without stratification. The Mantel-Haenzel test (log-rank) was used to compare the survival curves. A significance level of 5\% was used in all tests.

The fourth was a descriptive, cross-sectional computerized survey ${ }^{(20)}$ with 34 items organized into six sections. It aimed to survey 22 nurses to identify methods used to screen, manage, and monitor acute skin reactions within the radiation departments of an urban, northeastern teaching hospital and its network facilities and identify strategies to establish a mechanism for ongoing communication among the nurses to develop and implement an evidence-based protocol.
Nausea and vomiting were the second physical side effects reported. The fifth study ${ }^{(17)}$ was a survey with physicians, oncology nurses and patients conducted across five European countries. The aim was to analyze the participants' experiences on prescribing/recommending anti-emetic medication for nausea and vomiting induced by chemotherapy (CINV)/radiotherapy (RINV) and the patients' experiences on receiving orientation about medication use. A questionnaire assessed the incidence and impact of CINV/RINV, anti-emetic usage and compliance, and attributed importance of anti-emetic medication. Patient-physician and patientoncology nurse discussions in the UK were compared with the rest of the European countries using 95\% confidence intervals. The Student's $t$ test was used to test for a perceptual gap between physicians, oncology nurses and patients.

In the sixth study, cross-sectional design research ${ }^{(19)}$ described how to avoid radiotoxicity (dehydration) through the intake of two liters of fluid per day during treatment and in the seventh, a systematic literature review ${ }^{(21)}$ aimed at analyzing the strategies that facilitate self-care in promoting self-care and comfort developed by cancer patients undergoing chemotherapy/radiotherapy. The method used was the PI(C)OD methodology, resulting in 10 articles included. A longitudinal correlation study of this systematic review ${ }^{(21)}$ shows that $77.8 \%$ of the participants affirmed using rest as a self-care strategy for fatigue and $45.7 \%$ used napping.

The studies focusing on the nursing care process reinforce the need of a planned nursing consultation, communication and health professional relationship. The eighth study was conducted as a methodological descriptive research ${ }^{(16)}$, for the validation of an educational manual directed to patients with head and neck cancer submitted to radiotherapy. The validation was carried out by 15 experts in the thematic area of the educational manual and by two professionals of linguistics and publicity. An agreement index of at least $80 \%$ was considered to guarantee the validation of the material ${ }^{(16)}$.

The ninth ${ }^{(22)}$ article explored the tensions between competing demands and going beyond professional courtesy to empathic engagement through a case report. There is an interactive discussion, in which attendees share insights and experiences, and discuss thoughts and feelings. The rounds foster patient-centered care, enhance communication, and improve the connection between patients and caregivers.

The tenth was an exploratory, descriptive, cross-sectional study ${ }^{(18)}$, aimed to analyze nursing care for cancer patients with oral mucositis guided by the nursing process (NP). It was carried out with 213 patients undergoing chemotherapy and/or radiotherapy in two oncology services. Only $25.3 \%$ of patients reported having received nurses' guidelines during treatment and after, according to the patients' conception, significant difference in the quality of nursing care between public and private services. Knowing oral mucositis condition is essential for the formulation of nursing care aimed at prevention, based on the establishment of an oral care plan.

Only two qualitative studies were included in this systematic review ${ }^{(23-24)}$. The first aimed to implement and evaluate a Care Program for Palliative Radiotherapy 
(CPPR) in the Outpatient Clinic of the Department of Radiotherapy at the Erasmus MC-Cancer Institute in Rotterdam using participatory action research (PAR). The study, among other aspects, analyzed the reasons for developing a new care program for patients receiving palliative radiotherapy, the designed and implemented process, the patients and healthcare professionals' outcomes perceptions including satisfaction, attention to patients' needs, and sustainability of the program. The study consisted of the application of a regulative cycle method usually applied to solve context-specific and unique problems in practice developed in four steps: (I) problem choice and diagnosis, (II) plan, (III) implementation, and (IV) evaluation. The participants were two researchers from the Centre of Expertise for Innovations in Care of Rotterdam University, and eight healthcare professionals of the Department of Radiotherapy: a nurse manager, a staff nurse, a ward nurse, two radiotherapists, two radiographers and the nurse practitioner (project leader) ${ }^{(24)}$. The second was a sociological phenomenology study ${ }^{(23)}$ based on Alfred Schutz with thirteen women submitted to brachytherapy in two radiotherapy services using a semi-structured interview.

\section{BIAS RISK ASSESSMENT}

Assessment of the methodological quality of the quantitative studies and the instruments (Checklist for Analytical Systematic Reviews and Research Syntheses, cross-sectional studies, quasi-experimental studies/non-randomized experimental studies, experimental studies/randomized studies, randomized controlled trials) revealed that the studies included in the review obtained scores of five to six points, making them reliable and methodologically sound, therefore with a lower risk of bias. Questions in relation to confounding factors were considered not applied in some studies. The qualitative studies were assessed by tools (text and opinion and qualitative research) with questions one to ten and included the studies that obtained scores of seven to ten points. The studies were considered methodologically rigorous and therefore included in the review. If there was an "unsure" or "not applicable" rating on any of the predetermined key criteria, the pair review was included in the discussion whether to exclude or include the study.

\section{NARRATIVE SYNTHESIS OF QUANTITATIVE RESEARCH FINDINGS}

The narrative synthesis was built focusing on nursing interventions considering biopsychosocial aspects of nursing care. To prevent and treat skin damage, the results of studies have indicated the use of Calendula officinalis ${ }^{(13,20)}$ and honey thyme ${ }^{(14)}$. The results of the randomized double-blind controlled clinical trial indicate that Calendula showed better therapeutic response than the essential fatty acids in the prevention and treatment of radiodermatitis. Through the Kaplan-Meier survival curve. It was observed that essential fatty acids group has always remained below the Calendula group survival curve, due to the lower risk of developing radiodermatitis grade 1 . However, the results of a study ${ }^{(19)}$ describe the use of essential fatty acids and observation of relief of cutaneous symptoms, but no evidence of effectiveness. In the descriptive study results, a cross-sectional computerized survey ${ }^{(20)}$ only suggests the use of the experience of nurses without evaluation of effectiveness. In a descriptive, cross-sectional computerized survey ${ }^{(20)}$, nurses suggest that there is a strong justification to the need of a skin care protocol including the type and frequency of skin assessments and recommended treatments for prevention and management of common skin problems associated with radiation dermatitis. They suggest using scales and the most referred were Radiation Therapy Oncology Group/Eastern Cooperative Oncology Group scale, the NCI scale and Skin Toxicity Assessment Tool. In this study, effectiveness was not performed. The most suggested products to skin care are: Hydrophor, R1 Gel, Lubriderm, Aquaphor, R2 Lotion, Udderly Smooth, Saline Soaks, Aloe Vera, Viglilon, Cool Soaks, Calendula Cream, Mepilex, Vaseline Gauze, Lindi Products, Mepilex Lite, Hydrogel pads, Carrington Gel sheets, Mepitel, Xeroform Gauze, Sarna Lotion, Telfa, Benadryl Cream and Hydrocortisone Cream. In another study ${ }^{(20)}$ they were cited to treat radiotoxicity and be used after a radiotherapy section. Patient adherence on use of chamomile tea was about $92 \%$. The reason was the low cost and beliefs about its use and results. As self-care, they recommend to avoid sun exposure, avoid shaving, use only electric razors, wear loose clothing, use mild soap and use baby shampoo. Associated with these actions in the study ${ }^{(19)}$, it is cited the cutting and cleaning of nails.

To prevent and treat mouth disorders as mucositis, the results of a randomized controlled trial (RCT) indicate that the use of thyme honey has a positive effect on the management of radiation-induced oral mucositis and quality of life in head and neck cancer patients ${ }^{(14)}$. Associated with this, another study of methodological development indicated oral hygiene as a protocol for prevention ${ }^{(16)}$.

To nausea and vomiting prevention and treatment, the results of a cross-sectional study show the prescription of antiemetics, according to guidelines of 30 minutes before, during and after radiotherapy and guidance on indication, mode of action, and reactions. Dosage is considered essential for adherence to treatment ${ }^{(17)}$.

\section{Pain/ODYNOPHAGIA}

A study's results ${ }^{(15)}$ show that a predictive model for clinical assessment of symptom severity based on guidelines for the indication of specific nursing interventions for the prevention of odynophagia, especially analgesia, may be effective. Evaluation before the start of the first fraction of radiotherapy allows nurses to plan appropriate interventions for patients at risk. In the study, it was verified that the evaluation done previously allowed to identify approximately $80 \%$ probability of patients that may need a prescription for odynophagia medication during the radiotherapy.

For use in pain control, a study ${ }^{(14)}$ showed that the mouth pain mean score on the intervention group at baseline was 5.4 \pm 2.6 , and then decreased one month after the completion of radiotherapy to $4.8 \pm 2.5$, and even more in the 6 th month to 
$0.7 \pm 0.6$. Mouth pain in the control group was $6.0 \pm 2.3$ at baseline and increased in the 1st month after the completion of radiotherapy $(7.4 \pm 1.6)$, and it also decreased $(2.2 \pm 1.4)$ in the 6 th month. The size of the difference on the mean mouth pain score between control and intervention group at six months, it was very high (Cohen's $d=1.98$ ) compared to the low difference at baseline (Cohen's d=0.24). The findings of this study provided evidence on the effectiveness of thyme honey in enhancing the effective management of mucositis in head and neck cancer patients during and after radiotherapy. Symptoms related to swallowing, drinking, eating, oral pain and weight loss were found to be statistically significant in the intervention group. The use of two methods of assessment (objective and subjective) provided greater comprehension of the problem of mucositis in this group of patients. The results demonstrated a significant reduction of grade 3 and grade 4 mucositis in the interventional group, a finding supported by the relevant literature. Previous studies demonstrated that honey could be considerably beneficial in reducing the overall severity of mucositis. The current study shows improved symptomatology, which clearly confirms the positive effect of honey on the general quality of life of the participants who used oral rinses with thyme honey.

\section{PATIENT=CENTERED CARE: PLANNED CARE}

In a cross-sectional study's results ${ }^{(19)}$, it was observed that nursing consultations contribute to the adherence of $90 \%$ of the patients to self-care recommendations and can contribute to a reduction of approximately $54 \%$ in the development of radiodermatitis. It's concluded that nursing consultations are important in the care of patients who undergo radiotherapy and can influence adherence to treatment and clarification of doubts about the therapeutic plan when associated with a nursing theory that enhances self-care. The results of a randomized systematic review study ${ }^{(21)}$ show that the use of Orem's self-care theory in nursing intervention proved to have a positive effect on minimizing stress reactions ( $p$ $=<0.05$ ) and suggested that a nursing intervention should be implemented for breast cancer patients receiving curative radiation therapy. The instruments used in the randomized study ${ }^{(25)}$ included in the review showed acceptable reliability with application of the Impact of Event Scale (IES-scale) (0.87), including the intrusion subscale (0.83) and the avoidance subscale (0.73). In the Oncology Treatment Toxicity Assessment Tool (OTTAT), reliability was 0.85, and for the Cancer Rehabilitation Evaluation System (CARES-sf) reliability ranged from 0.76 to 0.94 . Patients in the experimental group rated fewer distress reactions than the control group (p0,05). The IES items most frequently endorsed for the total sample were 'I thought about it when I didn't mean to' (55\%), 'Any reminder brought back feelings about it' (50\%) and 'I tried not to think about it' (40\%). In addition, another study $^{(21)}$ highlights self-care strategy for coping with social well-being is through a good support network (95.6\%), psychological health considered living (69.6\%), having physical health through periodic appointments marked (43.5\%) and a cognitive function preserved preserving the responsibility for their own health (43.5\%).
Reinforcing the need for nursing consultations to patients in radiotherapy ${ }^{(16)}$ and a system-wide standardized approach to the management of patients undergoing radiation therapy, it is suggested to have a skin care protocol that defines type and frequency of skin assessments, as well as recommended treatments for prevention and management of common skin conditions related to radiation dermatitis.

In a clinical case ${ }^{(22)}$, it was observed that patientcentered care (PCC) has necessary conditions like emotional intelligence and social dexterity to accommodate the nuances of each patient encounter. In addition to insight and empathy, it is needed to continuously reassess the strengths and weaknesses of patient-centered clinical relationships. Guarding the trust implicit in those relationships requires more social understanding than most medial trainees anticipate or seasoned practitioners give themselves credit for, but it is vital in meeting the expectations of our profession and our patients.

In radiotherapy nursing care, a nursing workflow is seen as the respect for the ideals of $\mathrm{PCC}^{(15)}$. It suggests that the use of a predictive model for pain medication for odynophagia prior to commencement of radiotherapy would support radiotherapy technologist nurses (RTNs) in directing nursing interventions towards patients at risk. In all models, the $95 \%$ confidence interval (from repeated cross-validation) for the estimated predictive accuracy was above the no-information rate of $67 \%$. Three multivariate logistic models were evaluated in repeated cross-validation: a manual-stepwise model and two supervised machine learning models. Overall predictive performance was good. Correct classification rates ranged from 0.82 to 0.84 , and areas under the receiver operator curve ranged from 0.83 to 0.85 . Model sensitivity (range: 0.92-0.97) was higher than model specificity (range: 0.58 0.63 ) but further validation of the models in clinical context is required.

\section{NARRATIVE SYNTHESIS OF QUALITATIVE RESEARCH FINDINGS}

In order for care to be focused on the patients' needs, it is suggested that the health team describes the responsibilities of Heath Care Professionals along the therapeutic itinerary starting from: first visit, location of the region to be treated, planning of the radiation session, and follow-up. Every stage should have a checklist defining the healthcare professionals' tasks in each stage. One example is a nursing protocol of paraplegic patients' care to guide nursing care and provide support throughout the radiation sessions including the end of treatment and transferences. To the transfer's care the study suggests a form with transfer information and about the patients' conditions from the nurse that provided the care to the physicians in outpatient radiotherapy referred ${ }^{(24)}$. Follow-up telephone calls are also suggested after 2 weeks by the nurse practitioner, in addition to the standard 4-week follow-up call performed by the radiotherapist and waiting room for patients and their relatives, giving more privacy, peace and quiet.

Another suggestion for focusing care on the patients' needs is the availability of a guiding manual on treatment and adverse reactions for both patients and referenced 
professional including an explanation about the treatment process $^{(24)}$. Experiences and acceptability towards nursing consultations are reported in the following findings.

FINDING 1 - THE IMPACT OF NURSING CONSULTATIONS ON RADIOTHERAPY

All interviewed health care professionals were confident that the program contributed to better communication with the patients. Patients indeed were very satisfied with the oral information and with the nurse practitioner's key role because the most important change was the pivotal role of the nurse practitioner with nursing consultations. She was the person responsible for many elements of the care program and coordination on radiotherapy including her own consultations based on a nursing protocol, in which she listened to the patients, informed them, and identified medical and psychosocial problems, as stated by one patient: "We had a comprehensive consultation with the nurse practitioner"(24). Patients express the desire to have information about the treatment itself once the disease has come into their lives, as stated by one patient:

"I think that coming to this consultation with you is good because we do not know how to say if we are going to be well or not, if this disease will have a cure (...). It was good for me because I got rid of my doubts. I think if I had not come to the consultation with the nursing staff it would have been even worse to face all this" ${ }^{(23)}$.

\section{FINDING 2 - EMPATHY (PSYCHOSOCIAL SUPPORT) AS THE LINK BETWEEN NURSE AND PATIENT}

Patients found that the psychosocial support explicitly introduced by the nurse practitioner was valuable. As one patient stated: "The consultation with the nurse was good because she talked to me, explained many things, but also asked about me, how I live, what I work in, and it was very $\operatorname{good}^{\prime \prime(23)}$.

\section{FINDING 3 - FOLLOW UP - THE CONTINUITY OF NURSING} CARE BY TELEPHONE

The program also included follow-up telephone calls after 2 weeks by the nurse practitioner, in addition to the standard 4-week follow-up call performed by the radiotherapist. The follow-up consultation with the nurse practitioner was appreciated by most patients. The nurse practitioner felt that the patients valued the 2-week telephone follow-up ${ }^{(24)}$.

\section{FINDING 4 - AMBIENCE: AN IMPORTANT FACTOR TO RADIOTHERAPY PATIENT-CENTERED CARE, BUT NOT WITHOUT NURSING CONTACT}

Additionally, with the help of external funding, a new waiting room was provided for patients and their relatives, giving more privacy, peace and quiet. Most patients considered the waiting times acceptable, even though they could be long. The new waiting room at the outpatient clinic was appreciated for the privacy it offered, but patients missed attention from the ward nurses ${ }^{(24)}$.
FINDING 5 - COMMUNICATION TOOLKITS: A BOOKLET AS A FORM TO INTRODUCE THE RADIOTHERAPY SERVICE CARE AND TREATMENT

Lastly, an information booklet was developed for both patients and referring healthcare professionals, including a photo reportage showing how treatment sessions proceed ${ }^{(24)}$. In summary, the findings show that most patients consider nursing consultation a valid way to understand the illness and treatment process. These results suggest social acceptability of the intervention (nursing consultation) among the study participants.

\section{DISCUSSION}

Changes in the context of nursing care in radiotherapy and calls for nursing care reform have been reported, but still are not enough to really change to an effective patientcentered nursing care in radiotherapy. However, nursing interventions, such as nursing consultations need to be more evaluated to guide practice. In this Mixed-method Systematic Review, both Qualitative (QL) and Quantitative (QN) the main nursing interventions found were nursing consultation with or without nursing theory; skin care and control strategies for symptoms/side effects. Finally, communication process in nursing care research has shown that nursing consultations in radiotherapy have a meaningful contribution and shows to be effective to patient-centered care for patients with head and neck, breast and lung cancer.

This systematic review indicates that nursing consultations contribute to patient adherence to self-care recommendations and reduce the development of adverse effects such as radiodermatitis ${ }^{(13-14,19-20)}$, odynophagia ${ }^{(14-15)}$, mucositis $^{(14)}$, nausea/vomiting, fatigue ${ }^{(17,21)}$, and dehydration ${ }^{(21)}$. When associated with nursing theories and a workflow (standardization of the method), it can enhance self-care and decrease and/or prevent adverse reactions and treatment-related signs/symptoms ${ }^{(19)}$ and psychological changes, such as stress, in addition to respecting the ideals of the patient-centered model of care ${ }^{(15)}$. Nursing consultations in radiotherapy should be performed according to the principles of patient-centered care, considering skills, such as emotional and social intelligence. They are needed because they are made possible by empathy ${ }^{(22)}$. Patients in the experimental group rated fewer distress reactions than the control group. As a coping strategy, reinforced in nursing consultations, patients use a support network (95.6\%), live life to the fullest (69.6\%), periodic appointments (43.5\%), and assume responsibility for their own health $(43.5 \%)^{(21)}$.

Guidelines in nursing radiotherapy working with patientcentered care is grounded on the provision of care that is respectful of, and responsive to individual patient preferences, needs and values; ensuring that patients' values guide all clinical decisions. These decisions can be done in a nursing plan and the patient assessment could include physical assessment, and psychosocial and psychological (emotional, spiritual, mental) needs. It is reinforced that nursing consultations should be comprehensive and the assessment conducted and documented at baseline (first contact) and when there is a 
change in patient status which includes but is not limited to specific assessment related to the radiation therapy treatment area. The focus of nursing consultation is to review patients after the procedure and assess them, using a consultation checklist, for adverse events ${ }^{(26)}$.

It should be emphasized that some nursing interventions, when planned, may contribute to the evaluation of potential risks for the development of adverse effects. Working with predictive models for pain control in odynophagia has shown to be effective with a $95 \%$ confidence interval (from repeated cross-validation) for the estimated predictive accuracy above the no-information rate of $67 \%^{(15)}$. Evaluation before the start of the first fraction of radiotherapy allows nurses to plan appropriate interventions for patients at risk. In the study, it was verified that the evaluation done previously allowed to identify approximately $80 \%$ probability of the patient that may need prescription of odynophagia medication during the radiotherapy ${ }^{(15)}$. Model sensitivity (range: $0.92-0.97$ ) was higher than model specificity (range: $0.58-0.63$ ) but, further validation of the models in clinical context is required.

As far as skin care and mouth interventions are concerned, results from the use of calendula ${ }^{(13,20)}$ and honey thyme $^{(14)}$ have been shown to be effective both for prevention and for the treatment of radiodermatitis and mucositis, respectively. Compared with essential fatty acids, calendula showed to be more effective in relation to the survival curve with lower risk of developing radiodermatitis grade 1 .

A systematic review study ${ }^{(27)}$ of randomized clinical trials also showed a significant effect favoring honey treatment in moderate-severe oral mucositis (odds ratios: $0.25,95 \%$ confidence intervals: 0.14 to 0.46 ), but there was still substantial heterogeneity $(\mathrm{P}=0.00, \mathrm{I} 2=77.5 \%)$. In this study, honey could improve the therapy efficacy of moderate to severe oral mucositis and not only did not increase the risk of adverse effects, but also reduced the onset time of oral mucositis ${ }^{(27)}$ On the other hand, one aspect of the use of thyme honey should considered pollinatization. Evidence about this process shows that species of the Lamiaceae (Labia-tae) family pollinated by bees and a relatively wide spectrum of insects specially the genre Thymus L. in particular (Thymus loscosii Willk, Thymus vulgaris L., Thymus granatensis Boiss, Thymus arundanus Willk) produce a nectar that is rich in phenylalanine and sucrose. This combination makes this nectar more attractive to bees and can reflect the co-evolution between these plants and their main pollinators. This condition may cause fluctuations on nectar production and its characteristics considerably and in response to subtle changes in the environment, such as wind, temperature and soil moisture and maybe the position of the flower on the plant and pollinator activity. This pollination condition may cause interventions on floristic composition and be a determinant factor in a honey chemical content clearly influencing its sensory characteristics. In agriculture studies about physicochemical values and the pollen spectra obtained from thyme honey has showed correlation with the geographical origin of the honey. The study included in this review affirm as quality control of thyme honey a single supplier but does not mention if the beekeepers and their associations to produce honey with a geographically defined label of origin were considered in the chemical analysis of main species and families of plant. This condition maybe can impact on the effectiveness of use in skin care and mouth ${ }^{(28)}$.

Another study showed that pain relief rate of moderate and severe pain was higher with the use of OxyContin and had a good therapeutic effect on oral mucosal pain and integrated nursing intervention. Early intervention for pain, timely identification of adverse reactions to OxyContin and standardized treatment of pain can effectively improve the quality of life. The result of this study reinforces the importance of nursing consultations and strengthens the use of a nursing plan to prevent and control mucosal pain ${ }^{(29)}$.

It's important to highlight that in the studies analyzed in this review, the substances were assessed in isolation rather than associated with others. Other non-randomized studies suggest other products for prevention and treatment of skin reactions: Hydrophor, R1 Gel, Lubriderm, Aquaphor, R2 Lotion, Udderly Smooth, Saline Soaks, Aloe Vera, Viglilon, Cool Soaks, Mepilex, Vaseline Gauze, Lindi Products, Mepilex Lite, Hydrogel pads, Carrington Gel sheets, Mepitel, Xeroform Gauze, Sarna Lotion, Telfa, Benadryl Cream, and Hydrocortisone Cream ${ }^{(20)}$, but without an effectiveness study. Chamomile use was shown to be more acceptable by patients due to its low cost, including the beliefs in the results ${ }^{(19)}$. Another study shows the efficacy of chamomile through a network meta-analysis and suggests that, in comparison with usual care, chamomile ranked the best for the efficacy of moderate-severe oral mucositis treatment (OR:0.05, 95\%; IC: $0.01-0.46)^{(27)}$. The incidence of radiodermatitis in cancer patients is about $95 \%$ during treatment and patient education strategies should be applied in nursing consultation to early recognition of skin changes and an early intervention plan. Consistent symptom management recommendations can improve dermatologic adverse event strategies ${ }^{(30)}$. Regarding prophylaxis, a study showed that the use of topical steroids in the period after protocol implementation led to the development of less grade 2 of radiodermatitis in patients ${ }^{(31)}$.

A key point that should be investigated is the effectiveness of compost products. Many pharmaceutical companies are in constant development of oncology products with the main aim on business. An example of it is NS-21, a product of an Australian Pharmaceutical presented in a natural cortisone-free cream that includes calendula, aloe vera, allantoin, vitamin $\mathrm{E}$, beta-glucan, hydrolyzed soy protein, grape seed oil, zinc, honey, emu oil, avocado oil, jojoba oil, rose hip oil, urea, among other components ${ }^{(32)}$.In a randomized control trial study ${ }^{(32)}$, the efficacy of this cream (NS-21) revealed that it is well tolerated and effective for the maintenance of skin moisture, but there is no statistical significance in the reduction of radiation dermatitis risk. So as a prophylactic action, it does not reduce the severity of radiation dermatitis.

To nausea and vomiting prevention and treatment, the cross-sectional study's results showed that the prescription of antiemetics - according to guidelines 30 minutes before, during and after radiotherapy - and guidance on indication, mode of action, reactions and posology are considered essential for adherence to treatment ${ }^{(17)}$. Few studies show 
interventions for the prevention and management of nausea and vomiting induced by radiotherapy, mainly due to these underestimated symptoms. Between $50 \%$ and $80 \%$ of patients undergoing radiotherapy experience nausea and/or vomiting, depending on the site of radiation ${ }^{(33)}$.

In dehydration conditions, the cross-sectional study's results ${ }^{(19)}$ describe how to avoid radiotoxicity through the intake of two liters of liquid per day during treatment.

In the results of a systematic review ${ }^{(21)}$ in a longitudinal correlational study, it was found that $77.8 \%$ of the participants affirmed using rest as a self-care strategy for fatigue and $45.7 \%$ used a "nap". Other nursing orientations ${ }^{(20)}$ identified to patient self-care were: avoid sun exposure; avoid shaving; use only electric razors, wear loose clothing, use mild soap, and use baby shampoo. Associated with these actions in the study ${ }^{(19)}$, it is cited the cutting and cleaning of nails. Not all these measures have high evidence level that can support the indication.

The limited number of primary studies identified thorough the search performed in this review, particularly RCTs and qualitative studies, was the greatest limitation.

\section{CONCLUSION}

The reviewers aimed to synthesize the best available evidence on the effectiveness and experiences of nursing interventions for the prevention and treatment of side effects in patients undergoing radiotherapy. A rigorous literature review and quality appraisal process was conducted and 12 studies were included in the review. The studies were classified as having high methodological quality and provided evidence of effectiveness, particularly, about skin care with the use of calendula to radiodermatitis and honey thyme to mucositis and a meaningful result by patients. Although we have found studies about the use of them we did not find one that defended the use of a protocol. Nursing care plans and consultations were suggested as an important intervention to prevent and treat side effects of radiotherapy. A person-centered approach increases the likelihood of a coherent chain of care where patients themselves do not have to navigate their way through the multi-professional organization of hospitals and other healthcare institutions.

The implications based on the quantitative studies of this review are limited due to the varied quality and the inability to conduct a meta-analysis. Furthermore, cost-effectiveness studies would help public health decision-makers to implement nursing interventions.

Nevertheless, the conclusions reached by analysis of the results from the included studies may contribute to expanding available knowledge and may be useful in decision making regarding nursing interventions and patient-centered care.

\section{RESUMO}

Objetivo: Sintetizar as melhores evidências disponíveis sobre a efetividade de intervenções de enfermagem no cuidado do paciente de radioterapia e sumarizar as evidências das experiências e aceitabilidade das intervenções reportadas pelos profissionais da saúde envolvidos na prevenção e tratamento dos efeitos colaterais. Método: Revisão sistemática de métodos mistos. São apresentadas pesquisas quantitativas e qualitativas. Resultados: 12 estudos publicados nos últimos cinco anos foram incluídos. A maioria das intervenções encontradas focaram em cuidados com a pele, cuidados orais, náuseas e vômitos relacionados às consultas de enfermagem. De acordo com um alto nível de evidência e grau de recomendação dos estudos, o uso da Calendula officinalis e mel de tomilho foram considerados eficientes na prevenção e no tratamento da radiodermatite e da mucosite, respectivamente. Conclusão: A qualidade das evidências de intervenções de enfermagem é fraca. Mesmo que existam estudos com um desenvolvimento forte e um alto grau de evidência, as publicações sobre intervenções de enfermagem não são suficientes e com alta qualidade para dar suporte ao planejamento de cuidado centrado no paciente de forma eficaz.

\section{DESCRITORES}

Neoplasias; Radioterapia; Enfermagem Oncológica; Assistência Centrada no Paciente; Revisão.

\section{RESUMEN}

Objetivo: Sintetizar la mejor evidencia disponible sobre la efectividad de las intervenciones de enfermería en la atención de pacientes en radioterapia y resumir la evidencia de las experiencias y aceptabilidad de las intervenciones reportadas por los profesionales de la salud involucrados en la prevención y tratamiento de efectos colaterales. Método: Revisión sistemática de métodos mixtos. Se presentan investigaciones cuantitativas y cualitativas. Resultados: se incluyeron 12 estudios publicados en los últimos cinco años. La mayoría de las intervenciones encontradas se centraron en cuidados de la piel, cuidados bucales, náuseas y vómitos relacionados con las consultas de enfermería. Según un alto nivel de evidencia y grado de recomendación de los estudios, el uso de Calendula officinalis y miel de tomillo se consideró eficaz en la prevención y el tratamiento de la radiodermatitis y la mucositis, respectivamente. Conclusión: La calidad de la evidencia de las intervenciones de enfermería es pobre. Si bien existen estudios con fuerte desarrollo y alto grado de evidencia, las publicaciones sobre intervenciones de enfermería no son suficientes y de alta calidad para respaldar una planificación de la atención centrada en el paciente de manera eficaz.

\section{DESCRIPTORES}

Neoplasias; Radioterapia; Enfermería Oncológica; Atención Dirigida al Paciente; Revisión.

\section{REFERENCES}

1. World Health Organization. WHO guidance note: comprehensive cervical cancer prevention and control: a healthier future for girls and women. Geneva: WHO; 2017.

2. Brasil. Ministério da Saúde; Instituto Nacional do Câncer José Alencar Gomes da Silva. Incidência do câncer no Brasil: estimativas 2017. Rio de Janeiro: INCA; 2018.

3. Zanatta JP, Zanella L, Kurtz GST, Gabardo BB, Roman A, Pastorello J. Trigeminal cave brain metastasis from prostate adenocarcinoma: case report and review of the literature. Arq Bras Neurocir. 2018;37:330-3. doi: https://doi.org/10.1055/s-0038-1676525 
4. Brasil. Ministério da Saúde; Instituto Nacional do Câncer José Alencar Gomes da Silva. Incidência do câncer no Brasil: estimativas 2018. Rio de Janeiro: INCA; 2019.

5. Gilman AG, Hardman J, Limbird LG, Terapi GDF. As bases farmacológicas da terapêutica. 11ª ed. Porto Alegre: Artmed; 2010.

6. Salvajoli JV, Souhami L, Faria SL. Radioterapia em oncologia. São Paulo: Medsi; 2013.

7. Tannure MC, Pinheiro AMSAE. Sistematização da assistência de enfermagem: guia Prático. $2^{\mathrm{a}}$ ed. Rio de Janeiro: Guanabara Koogan; 2010.

8. Salimena AMO, Teixeira SR, Amorim TV, Paiva ACPC, Melo MCSC. Estratégias de enfrentamento usadas por enfermeiros ao cuidar de pacientes oncológicos. Rev Enferm UFSM. 2013;3(1):8-16. doi: http://dx.doi.org/10.5902/217976926638

9. Conselho Federal de Enfermagem. Resolução COFEN-211/1998. Dispõe sobre a atuação dos profissionais de enfermagem que trabalham com radiação ionizante [Internt]. Brasília: COFEN; 1998 [citado 2019 jun. 22]. Disponível em: http://www.cofen.gov.br/resoluocofen-2111998_4258.html

10. Aromataris E, Munn Z, editors. JBI Manual for Evidence Synthesis. Adelaide: JBI; 2020. doi: https://doi.org/10.46658/JBIMES-20-01

11. Moher D, Liberati A, Tetzlaff J, Altman DG; PRISMA Group. preferred reporting items for systematic reviews and meta-analyses: the PRISMA statement. PLoS Med. 2009;6(7):e1000097. doi: https://doi.org/10.1371/journal.pmed.1000097

12. Karino ME, Felli VE. Enfermagem baseada em evidências: avanços e inovações em revisões sistemáticas. Ciênc Cuid Saúde. 2012;11 Supl:11-5. doi: https://doi.org/10.4025/cienccuidsaude.v11i5.17048

13. Schneider F, Danski MT, Vayego SA. Usage of Calendula officinalis in the prevention and treatment of radiodermatitis: a randomized double-blind controlled clinical trial. Rev Esc Enferm USP. 2015;49(2):221-8. doi: http://dx.doi.org/10.1590/S0080-623420150000200006

14. Charalambous M, Raftopoulos V, Paikousis L, Katodritis N, Lambrinou E, Vomvas D, et al. The effect of the use of thyme honey in minimizing radiation - induced oral mucositis in head and neck cancer patients: a randomized controlled trial. Eur $\mathrm{J}$ Oncol Nurs. 2018;34:89-97. doi: https://doi.org/10.1016/j.ejon.2018.04.003

15. Olling K, Nyeng DW, Wee L. Predicting acute odynophagia during lung cancer radiotherapy using observations derived from patientcentered nursing care. Techn Innov Patient Support Radiation Oncol. 2018;5:16-20. doi: https://doi.org/10.1016/j.tipsro.2018.01.002

16. Cruz FOAM, Ferreira EB, Vasques Cl, Mata LRF, Reis PED. Validação de manual educativo para pacientes com câncer de cabeça e pescoço submetidos à radioterapia. Rev Latino Am Enfermagem. 2016;24:e2706. doi: http://dx.doi.org/10.1590/1518-8345.0949.2706

17. Vidall C, Fernández-Ortega P, Cortinovis D, Jahn P, Amlani B, Scotté F. Impact and management of chemotherapy radiotherapy-induced nausea and vomiting and the perceptual gap between oncologists/oncology nurses and patients: a cross-sectional multinational survey. Support Care Cancer. 2015;23:3297-305. doi: https://doi.org/10.1007/s00520-015-2750-5

18. Araújo SNM, Luz MHBA, Silva GRF, Andrade EMLR, Nunes LCC, Moura RO. O paciente oncológico com mucosite oral: desafios para o cuidado de enfermagem. Rev Latino Am Enfermagem. 2015;23(2)267-74. doi: http://dx.doi.org/10.1590/0104-1169.0090.2551

19. Andrade KBS, Francz ACL, Grellmann MS, Belchior PC, Oliveira JA, Wassita DN. Nursing consultation: evaluation of adherence to selfcare in patients undergoing radiotherapy. Rev Enferm UERJ. 2014;22(5):622-8. doi: http://dx.doi.org/10.12957/reuerj.2014.11227

20. Oddie K, Pinto M, Jollie S, Blasiak E, Ercolano E, McCorkle R. Identification of need for an evidence-based nurse-led assessment and management protocol for radiation dermatitis. Cancer Nurs. 2014;37(2):37-42. doi: https://doi.org/10.1097/NCC.0b013e3182879ceb

21. Silva JMC, Ribeiro PPSV. Estratégias de autocuidado das pessoas com doença oncológica submetidas a quimioterapia/radioterapia e a sua relação com o conforto. Enferm Global. 2015;37:384-400. doi: https://doi.org/10.6018/eglobal.14.1.206591

22. Schapira L, Blaszkowsky LS, Cashavelly BJ, Kim CY, Riley JP, Wold MC, et al. Caring for One of Our Own. The Oncologist. 2014;19:5459. doi: http://dx.doi.org/10.1634/theoncologist.2014-0079

23. Araújo CRG, Rosas AMMTF, Menezes HF, Pinto ACS, Rodrigues BMRD. The phenomenon lived by women in nursing consultation in the gynecological brachytherapy. Texto Contexto Enferm. 2017;26(2):e00140016. doi: http://dx.doi.org/10.1590/0104-07072017000140016

24. Sande CVMVNV, Braat C, Visser AP, Delnoij DMJ, Staa AL. Why a carefully designed, nurse-led intervention failed to meet expectations: the case of the Care Programme for Palliative Radiotherapy. Eur J Oncol Nurs. 2014;18:151-8. doi: http://dx.doi.org/10.1016/j. ejon.2013.11.005

25. Wengström YY, Häggmark C, Strander H, Forsberg C. Effects of a nursing intervention on subjective distress, side effects and quality of life of breast cancer patients receiving curative radiation therapy: a randomized study. Acta Oncol. 1999;38(6):763-70. doi: https://doi. org/10.1080/028418699432923

26. National Health Service. Nottingham University Hospitals.. Guidelines for use with oncology patients receiving selective internal radiotherapy [Internet]. London; 2018 [cited 2019 Aug 28]. Available from: https://www.nuh.nhs.uk/download.cfm?doc=docm93jijm4n531

27. Yang C, Gong G, Jin E, Han X, Zhuo Y, Tang S, et al. Topical application of honey in the management of chemo/radiotherapy induced oral mucositis: a systematic review and network meta-analysis. Int J Nurs Stud. 2019;89:80-7. doi: https://doi.org/10.1016/j.ijnurstu.2018.08.007

28. González-Porto AV, Arroyo TM, Esteban CB. How soil type (gypsum or limestone) influences the properties and composition of thyme honey. SpringerPlus. 2016;5:1663. doi: 10.1186/s40064-016-3243-9

29. Hu W, Chen L, Wang C, Guo L, Hua X, Cai Y, et al. Standardized nursing and therapeutic effect of oxycontin on oral mucosal pain in nasopharyngeal carcinoma patients. J Cancer Res Ther. 2018;14:1594-9. doi: https://doi.org/10.4103/jcrt.JCRT_551_18

30. Seité S, Bensadoun RJ, Mazer JM. Prevention and treatment of acute and chronic radiodermatitis. Breast Cancer. 2017:9:551-7. doi: http:// dx.doi.org/10.2147/BCTT.S149752

31. Lucas AS, Lacouture M, Thompson J, Schneider SM. Radiation Dermatitis - A prevention protocol for patients with breast cancer. Clin J Oncol Nurs. 2018;22(4):429-37. doi: https://dx.doi.org/10.1188/18.CJON.429-437 
32. Chou HL, Shueng PW, Liao LJ, Hsu CX, Kuo DY, Lo WC, et al. Prophylactic NS-21 maintains the skin moisture but does not reduce the severity of radiation dermatitis in patients with head and neck cancer: a randomized control trial. Radiat Oncol. 2019;14:90. doi: https:// doi.org/10.1186/s13014-019-1302-4

33. Feyer PC, Maranzano E, Molassiotis A, Roila F, Clark-Snow RA, Jordan K. Radiotherapy-induced nausea and vomiting (RINV): MASCC/ ESMO guideline for antiemetics in radiotherapy: update 2009. Support Care Cancer. 2011;19:5-14. doi: https://doi.org/10.1007/s00520010-0950-6 